\title{
Novel Polyketide Metabolites from Streptomyces rimosus Mutant Strain R1059
}

\author{
Myrna A. Deseo, Iain S. Hunter, Peter G. Waterman
}

Received: February 10, 2005 / Accepted: November 28, 2005

(C) Japan Antibiotics Research Association

\begin{abstract}
Three novel polyketide metabolites were isolated from laboratory-scale fermentation of the Streptomyces rimosus mutant strain R1059. Structural elucidation of the compounds was based on NMR experiments. The compounds were characterized as naphthalene derivatives: ( $\mathrm{rel}$ )- $4 \beta, 8$-dihydroxy- $3 \alpha$ hydroxymethyl- $4 \alpha$-methyl-1,2,3,4-tetrahydronaphthalene1-one (1), $4 \xi, 8$-dihydroxy-3-hydroxymethyl-4 $\xi$-methyl-1,4dihydronaphthalene-1-one (2) and (rel)-4 $\beta, 8$-dihydroxy$3 \alpha$-O-[ $\alpha$-glucopyranosyl]hydroxymethyl- $4 \alpha$-methyl1,2,3,4-tetrahydronaphthalene-1-one (3). The compounds isolated appear to be derived via a shorter polyketide backbone than oxytetracycline (4), the normal end-product made by the parent of this strain. Compound $\mathbf{3}$ was the glucoside of 1 and must be formed as a post-PKS reaction by the activation of a glycosyl transferase, which has not been reported in this species before.
\end{abstract}

Keywords polyketide, Streptomyces rimosus, glycosyl transferase, novel metabolite, mutant

The aerobic soil bacterium Streptomyces rimosus produces the polyketide antibiotic oxytetracycline (OTC). S. rimosus R1059 is a mutant derived from S. rimosus M4018, a strain that has been used for the commercial production of OTC [1]. This mutant strain was unable to convert 6methylpretetramid (6-MPT) or 4-hydroxy-6-MPT (the first tetracyclic products on the OTC pathway) to OTC. Cosynthesis studies assigned this mutant (otc-151) to a

M. A. Deseo (Corresponding author), P. G. Waterman: Centre for Phytochemistry and Pharmacology, Southern Cross University, Lismore, NSW 2480, Australia, E-mail: mdeseo@scu.edu.au

M. A. Deseo: National Institute of Molecular Biology and defined gene group (otcZ) [2]. Subsequently, the otcZ151 mutant was shown to be complemented by a short segment of the otc cluster, when cloned in a low copy number vector [3]. This region encodes a methylase, so the otcZ151 mutant is presumed to be blocked at either the C-6 methylation or the C-4 amino methylation step of the OTC biosynthetic scheme. Until now, it has not been possible to infer which of these two steps might be blocked.

While these findings may indicate why S. rimosus R1059 does not produce OTC, there have been no studies to determine what metabolites it does produce. In this study, we have identified three major products from R1059, one of which was a glucosidic polyketide.

\section{Results and Discussion}

The fermentation broth was extracted with ethyl acetate and fractionated by flash and gel filtration chromatography to give three compounds.

The ${ }^{1} \mathrm{H}$ NMR spectral data of $\mathbf{1}$ (Table 1) showed three aromatic proton signals $(1 \mathrm{H}$ each) in the region $c a . \delta$ 6.8 7.2 with coupling constants indicating that they were arranged in an $A B C$ pattern. Other signals suggested a methyl on a quaternary carbon and oxymethylene, methylene and methine $s p^{3}$ protons. The ${ }^{13} \mathrm{C}$ NMR spectrum (Table 1) showed 12 carbon atoms: $s i x ~ s p^{2}$ (three quaternary and three tertiary) carbons, a ketone $(\delta$ 205.6) and five $s p^{3}$ carbons (quaternary, methine, methylene, oxymethylene, methyl). The APCI-MS showed a fragment at $[\mathrm{M}+1]^{+}=223.3$ suggesting a molecular formula of

Biotechnology, University of the Philippines Los Baños, College, Laguna, Philippines

I. S. Hunter: Department of Pharmaceutical Sciences, University of Strathclyde, Glasgow G1 1XW, Scotland, U.K. 
<smiles>[R]C[C@@H]1C(=O)c2c(O)cccc2[C@@](C)(O)[C@H]1C</smiles>

1: $\mathrm{R}=\mathrm{OH}$

$3: R=\alpha-g l u c o s e$<smiles>CC1(O)C(CF)=CC(=O)c2c(O)cccc21</smiles><smiles>CN(C)[C@H]1C(O)=C(C(N)=O)C(=O)[C@@]2(O)C(O)=C3C(=O)c4c(O)cccc4[C@@](C)(O)[C@@]3(C)[C@H](O)[C@H]12</smiles>

4

$\mathrm{C}_{12} \mathrm{H}_{14} \mathrm{O}_{4}$, which, as only eleven protons attached to carbons were observed, suggested the presence of three hydroxyls.

Direct and long-range $\mathrm{H}-\mathrm{C}$ correlations, obtained by HCCobi and HMBC experiments, suggested that the twelve carbons formed a naphthalene skeleton with methyl and hydroxymethyl substituents. The significant ${ }^{2} J_{\mathrm{CH}}$ and ${ }^{3} J_{\mathrm{CH}}$ correlations are shown in Fig. 1a. The quaternary carbon signals at $\delta 163.5$ and 73.2 were assigned at the C-8 and C4 positions, respectively, with hydroxyl substituents on these carbons. The methyl group was also assigned to $\mathrm{C}-4$ on the basis of long-range correlations to C-3, C-4 and C4a. With C-4 substituents known, HMBC and COSY data revealed the methine at $\mathrm{C}-3$ with the hydroxymethyl attached, a methylene at $\mathrm{C}-2$ and the ketone at $\mathrm{C}-1$. Thus compound $\mathbf{1}$ is 4,8-dihydroxy-3-hydroxymethyl-4-methyl1,2,3,4-tetrahydronaphthalene-1-one.

The relative stereochemistry of $\mathbf{1}$ at C-2 and C-4 was established from coupling constants and by NOE diff experiments. The large coupling of $12.8 \mathrm{~Hz}$ between the methine proton at $\mathrm{H}-3$ and one of the $\mathrm{H}-2$ methylene protons at $\mathrm{C}-2$ ( $\delta$ 2.64) required a trans diaxial orientation. This orientation implied that the $-\mathrm{CH}_{2} \mathrm{OH}$ substituted at
C-3 had to be at the equatorial position. In the NOE experiments, the methyl attached to $\mathrm{C}-4$ showed strong enhancements of both the axial $\mathrm{H}-2$ proton and the equatorial C-3 oxymethylene, which requires that the methyl be on the same face of the molecule as the oxymethylene and has to be axial (Fig. 2). The nonequivalence of the methylene protons at $\mathrm{C}-2$ could be attributed to the carbonyl group at $\mathrm{C}-1$ and the asymmetry at C-3. The downfield C-2 methylene proton at $\delta 2.92$, which was at the equatorial position, would almost be in the same plane as the carbonyl group and would therefore lie in the deshielding zone of the carbonyl. The nonequivalence of the hydroxymethylene protons, on the other hand, suggested that the $\mathrm{C}-3-\mathrm{CH}_{2} \mathrm{OH}$ bond was not freely rotating. The axial orientation of the methyl group at $\mathrm{C}-4$ and the presence of the hydroxyl group of $-\mathrm{CH}_{2} \mathrm{OH}$ would cause steric hindrance. Consequently the structure of 1 can be further refined to ( $\mathrm{rel}$ )- $4 \beta, 8$-dihydroxy- $3 \alpha$ hydroxymethyl-4 $\alpha$-methyl-1,2,3,4-tetrahydronaphthalene1-one.

The APCI-MS of 2 gave $[\mathrm{M}+1]^{+}=221$, two MU less than 1 and suggesting the empirical formula of $\mathrm{C}_{12} \mathrm{H}_{12} \mathrm{O}_{4}$. The NMR data for $\mathbf{2}$ (Table 1) indicated a close similarity to 1 but with the methylene and $s p^{3}$ methine being replaced by $s p^{2}$ methine and quaternary carbons, respectively. From HMBC correlations, it was confirmed that the structure was the same as $\mathbf{1}$ but with a 2,3 double bond leading to assignment as $4 \xi$,8-dihydroxy-3-hydroxymethyl-4 $\xi$-methyl1,4-dihydronaphthalene-1-one (2), with the stereochemistry at C-4 unclear.

The EIMS of 3 showed $\mathrm{M}^{+}=384$, which suggested the empirical formula $\mathrm{C}_{18} \mathrm{H}_{24} \mathrm{O}_{9}$. A major fragmentation ion was observed at $m / z 222$, which corresponded to $\mathbf{1}$ after loss of a hexose sugar. The ${ }^{1} \mathrm{H}$ NMR of $\mathbf{3}$ (Table 2) showed close similarities with 1 plus several oxymethine protons typical of a pyranose sugar. The ${ }^{13} \mathrm{C}$ NMR spectrum of 3 showed 18 carbon signals and by subtracting the aglycone portion, there were 6 unassigned carbons, which represented the hexose sugar moiety. The ${ }^{13} \mathrm{C}$ NMR spectra also showed the presence of the anomeric carbon at $\delta 101.1$ indicating an $O$-glycoside [4]. An HSQC experiment showing direct $\mathrm{H}-\mathrm{C}$ correlations revealed the anomeric proton signal $c a \delta 4.82$, which was underneath the residual solvent peak of $\mathrm{CD}_{3} \mathrm{OD}$. The COSY-45 experiment was very useful in placing the oxymethine protons on the sugar moiety as shown in Table 2 . The ${ }^{3} J_{\mathrm{HH}}$ values of $9.1 \sim 9.8 \mathrm{~Hz}$ for the coupling of the hydroxymethine protons $\mathrm{H}-2^{\prime}$ to $\mathrm{H}-3^{\prime}, \mathrm{H}-3^{\prime}$ to $\mathrm{H}-4^{\prime}$ and $\mathrm{H}-4^{\prime}$ to $\mathrm{H}-5^{\prime}$ required that these protons were all axial, implying that the sugar was glucose. The second coupling of $3.7 \mathrm{~Hz}$ for $\mathrm{H}-2^{\prime}$ had to be associated with its coupling to the anomeric proton $\left(\mathrm{H}-\mathrm{1}^{\prime}\right)$, 
Table 1 NMR spectral data for compounds $\mathbf{1}$ and $\mathbf{2}$ in $\mathrm{CD}_{3} \mathrm{OD}$ (Bruker AMX400)

\begin{tabular}{|c|c|c|c|c|}
\hline \multirow{3}{*}{ C/H Position } & \multicolumn{2}{|c|}{ Compound 1} & \multicolumn{2}{|c|}{ Compound $\mathbf{2}$} \\
\hline & \multicolumn{2}{|c|}{ Chemical shift, ppm } & \multicolumn{2}{|c|}{ Chemical shift, ppm } \\
\hline & ${ }^{13} \mathrm{C}$ & ${ }^{1} \mathrm{H}(\mathrm{J}$ in $\mathrm{Hz})$ & ${ }^{13} \mathrm{C}$ & ${ }^{1} \mathrm{H}(\mathrm{J}$ in $\mathrm{Hz})$ \\
\hline 1 & 205.6 & & 191.3 & \\
\hline \multirow[t]{2}{*}{2} & 40.0 & $2.92, \mathrm{dd}(18.2,4.4)$ & 121.9 & $6.46, \mathrm{t}(1.8)$ \\
\hline & & $2.64, \mathrm{dd}(18.2,12.8)$ & & \\
\hline 3 & 48.3 & $2.42, \mathrm{~m}$ & 172.3 & \\
\hline 4 & 73.2 & & 71.6 & \\
\hline $4 a$ & 154.8 & & 153.4 & \\
\hline 5 & 116.9 & $7.22, \mathrm{dd}(7.7,1.1)$ & 117.7 & $7.27, \mathrm{dd}(7.8,1.0)$ \\
\hline 6 & 138.3 & $7.53, \mathrm{dd}(8.3,7.7)$ & 136.0 & $7.53, \mathrm{dd}(8.3,7.8)$ \\
\hline 7 & 117.2 & $6.82, \mathrm{dd}(8.3,1.1)$ & 116.9 & 6.84. dd $(8.3,1.0)$ \\
\hline 8 & 163.5 & & 163.1 & \\
\hline $8 a$ & 116.2 & & 115.1 & \\
\hline \multirow[t]{2}{*}{ 1"- $\mathrm{CH}_{2} \mathrm{OH}$} & 62.7 & $4.02, \mathrm{dd}(10.7,4.8)$ & 60.8 & 4.66, dd $(18.3,1.8)$ \\
\hline & & $3.63, \mathrm{dd}(10.7,4.8)$ & & $4.57, \mathrm{dd}(18.3,1.8)$ \\
\hline $1^{\prime \prime \prime}-\mathrm{CH}_{3}$ & 25.1 & $1.41, \mathrm{~s}$ & 33.9 & $1.57, \mathrm{~s}$ \\
\hline
\end{tabular}

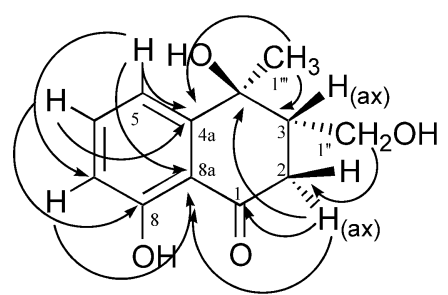

(a)

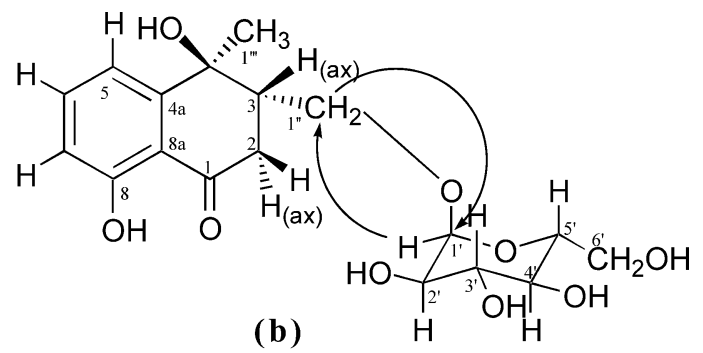

(b)

Fig. 1 Significant $\mathrm{HMBC}$ for: (a) compound $\mathbf{1}$; and (b) compound $\mathbf{3}$.

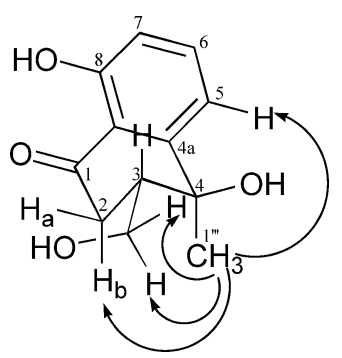

Fig. 2. Significant NOE correlations for $\mathbf{1}$ after irradiation of the methyl group $\left(4-\mathrm{CH}_{3}\right)$ at $\delta 1.41$.

which, given that $\mathrm{H}-2^{\prime}$ must be axial, required that the anomeric proton was in the equatorial position (i.e., $\alpha$ glucose). This was supported by the ${ }^{1} \mathrm{H}$ NMR data in DMSO- $d_{6}$ and pyridine- $d_{5}$ wherein the anomeric proton signal at $\delta 4.66$ and 5.38, respectively, gave a ${ }^{3} J_{\mathrm{HH}}$ value of $3.6 \mathrm{~Hz}$. Thus, the interglycosidic linkage was an $\alpha$ linkage, whereas plant glucosides are generally $\beta$ [5]. The glucose was placed on the 2-oxymethylene substituent of the tetrahydronaphthalene unit through observed ${ }^{3} J_{\mathrm{CH}}$ coupling in the HMBC spectrum (Fig. 1b). The relative stereochemistry of the aglycone portion of $\mathbf{3}$ was found to be the same as $\mathbf{1}$ by repetition of the NOE diff experiment outlined earlier. Thus, 3 is characterised as $(\mathrm{rel})-4 \beta, 8-$ dihydroxy-3 $\alpha-O$-[ $\alpha$-glucopyranosyl] hydroxymethyl $-4 \alpha-$ methyl-1,2,3,4-tetrahydronaphthalene-1-one.

The isolation of the glucoside (3) is of particular interest. The glycosylation of $\mathbf{1}$ to produce $\mathbf{3}$ seems to be a post-PKS reaction, with $\mathbf{2}$ as an intermediate in the production of $\mathbf{1}$. The presence of glycosyl transferases in Streptomyces is now well documented $[6,7,8]$ although it had not been 
Table 2 NMR spectral data for compound $\mathbf{3}$ in $\mathrm{CD}_{3} \mathrm{OD}$ (Bruker AVANCE DRX500)

\begin{tabular}{|c|c|c|c|c|}
\hline \multirow{2}{*}{ C/H Position } & \multicolumn{2}{|c|}{ Chemical shift, ppm } & \multirow{2}{*}{$\begin{array}{c}\operatorname{cosY} 45^{a} \\
\left(J_{H H}\right)\end{array}$} & \multirow{2}{*}{ NOE $\operatorname{diff}^{b}$} \\
\hline & ${ }^{13} \mathrm{C}$ & ${ }^{1} \mathrm{H}(\mathrm{J}$ in $\mathrm{Hz})$ & & \\
\hline 1 & 205.6 & & & \\
\hline \multirow[t]{2}{*}{2} & 40.5 & 3.06, dd $(18.2,4.4)$ & $\mathrm{H}_{\mathrm{b}}-2, \mathrm{H}-3$ & \\
\hline & & $2.76, \mathrm{dd}(18.2,12.8)$ & $\mathrm{H}_{\mathrm{a}}-2, \mathrm{H}-3$ & \\
\hline \multirow[t]{2}{*}{3} & 46.6 & $2.59, \mathrm{~m}$ & $\mathrm{H}-2$ & \\
\hline & & & $1 "-\mathrm{CH} 2 \mathrm{O}$ & \\
\hline 4 & 73.0 & & & \\
\hline $4 a$ & 154.9 & & & \\
\hline 5 & 116.9 & $7.24 \mathrm{dd}(7.8,1.0)$ & $\mathrm{H}-6$ & \\
\hline 6 & 138.3 & 7.53, dd $(8.3,7.8)$ & $\mathrm{H}-5, \mathrm{H}-7$ & \\
\hline 7 & 117.2 & $6.82, \mathrm{dd}(8.3,1.0)$ & $\mathrm{H}-6$ & \\
\hline 8 & 163.3 & & & \\
\hline $8 a$ & 116.2 & & & \\
\hline \multirow[t]{2}{*}{$1 "-\mathrm{CH}_{2} \mathrm{O}$} & 69.0 & $4.17, \mathrm{dd}(9.5,4.1)$ & $\mathrm{H}-3$ & \\
\hline & & $3.58^{c}$, dd $(9.5,5.5)$ & $\mathrm{H}-3$ & \\
\hline $1^{\prime \prime \prime}-\mathrm{CH}_{3}$ & 25.4 & $1.44, \mathrm{~s}$ & & $\mathrm{Hb}-2,1^{\prime \prime}-\mathrm{CH}_{2} \mathrm{O}, \mathrm{H}-5$ \\
\hline $1^{\prime}$ & 101.6 & ca. $4.82^{d}$ & $\mathrm{H}-2^{\prime}$ & \\
\hline $2^{\prime}$ & 74.1 & 3.42 , dd $(9.8,3.7)$ & $\mathrm{H}-1^{\prime}, \mathrm{H}-3^{\prime}$ & \\
\hline $3^{\prime}$ & 75.3 & $3.63, \mathrm{dd}(9.8,9.8)$ & $\mathrm{H}-2^{\prime} . \mathrm{H}-4^{\prime}$ & \\
\hline $4^{\prime}$ & 73.8 & $3.28, \mathrm{dd}(9.8,9.1)$ & $\mathrm{H}-3^{\prime}, \mathrm{H}-5^{\prime}$ & \\
\hline $5^{\prime}$ & 72.0 & $3.58^{\mathrm{c}}, \mathrm{m}$ & $\mathrm{H}-4^{\prime}, \mathrm{H}-6^{\prime}$ & \\
\hline \multirow[t]{2}{*}{$6^{\prime}$} & 62.9 & 3.82, dd $(11.9,2.3)$ & $\mathrm{H}-5^{\prime}$ & \\
\hline & & 3.67, dd $(11.9,6.1)$ & $\mathrm{H}-5^{\prime}$ & \\
\hline
\end{tabular}

a Proton showing $J_{H H}$ correlation to indicated proton.

${ }^{b}$ Proton showing NOE correlation to indicated proton.

${ }^{\mathrm{c}}$ Overlapping peaks

${ }^{\mathrm{d}}$ Underneath solvent peak

reported in S. rimosus. The isolation of the glucoside in this mutant strain suggests that the mutation has either activated a glycosyl transferase or the novel biochemical, $\mathbf{1}$, is now a substrate for a transferase that is normally expressed in $S$. rimosus, whereas the normal intermediate in OTC biosynthesis is not. This discovery indicates that $S$. rimosus should be included as a glycosylation-proficient host in 'search and discovery' projects that have the aim to use metabolic diversity to derive novel polyketide metabolites.

\section{Experimental}

\section{General}

NMR spectra were acquired on either a Bruker AMX400 $\left({ }^{1} \mathrm{H}, 400 \mathrm{MHz} ;{ }^{13} \mathrm{C}, 100.56 \mathrm{MHz}\right)$ or Bruker AVANCE DRX500 $\left({ }^{1} \mathrm{H}, 500 \mathrm{MHz} ;{ }^{13} \mathrm{C}, 125.77 \mathrm{MHz}\right)$ spectrometer using $\mathrm{CD}_{3} \mathrm{OD}$ as solvent and the residual solvent peak as reference. All experiments were run using the standard pulse sequences in the Bruker library. Mass spectra were recorded either on a JEOL JMS-AX505HA EIMS using a direct probe insert at $70 \mathrm{eV}$ or Agilent LC-MS 1100 series with binary pump, Phenomenex Luna C18 column $(150 \times 4.6 \mathrm{~mm}, 5 \mu)$, PDA and MS detectors using atmospheric pressure chemical ionisation (APCI) technique. UV data were recorded on a Hewlett Packard 8453 spectrophotometer. IR spectra were obtained using a Bruker Vector 33 FTIR spectrometer with the samples prepared as $\mathrm{KBr}$ discs. Separation of emulsified layers during extraction was done using a Beckmann J2-21 M/E refrigerated centrifuge. Flash chromatography was done using Biotage ${ }^{\mathrm{TM}}$ Flash 40 System with pre-packed silica cartridges. Compounds were detected by visualization under UV light ( $\lambda 254$ and $366 \mathrm{~nm}$ ) and by spraying with $0.5 \%$ anisaldehyde $-\mathrm{H}_{2} \mathrm{SO}_{4}$ reagent followed by heating on commercially-prepared TLC plastic sheets with Merck Si gel $60 \mathrm{~F}_{254}$ developed using $\mathrm{CHCl}_{3}-\mathrm{MeOH}-\mathrm{H}_{2} \mathrm{O}$ $(9: 6: 0.3, \mathrm{v} / \mathrm{v})$ as mobile phase. 


\section{Organism and Fermentation}

The mutant strain S. rimosus R1059 was obtained from the stock cultures of Prof. Iain S. Hunter, Dept. Pharmaceutical Sciences, University of Strathclyde, Glasgow, Scotland, U.K. This OTC-blocked mutant was derived from $S$. rimosus M4018, which has been used for the commercial production of OTC [1]. The genetic lesion otc $Z$ was first isolated by Rhodes et al. [2] in autotrophic strains and then recombined into a prototrophs, which was used for this work. The strain was grown on trypticase soya broth (TSB) agar (30 $\mathrm{g}$ trypticase soya broth powder, $15 \mathrm{~g}$ agar, made up to 1 liter with distilled water) on Petri plates incubated at $30^{\circ} \mathrm{C}$ for $6 \sim 10$ days. A loopful was taken from the stock culture and transferred on the plate and a single healthy colony was selected and streaked on several agar plates and allowed to sporulate. The spores were collected and transferred into several TSB agar slants and incubated at $30^{\circ} \mathrm{C}$ for $6 \sim 10$ days. The spores were scraped off from the agar surface with a sterile cow syringe using $5 \mathrm{ml}$ sterile water per slant and filtered as described in the protocol of Hopwood et al. [9], to remove the agar debris.

Two $\mathrm{ml}$ of the filtered spore suspension were inoculated into $25 \mathrm{ml}$ of vegetative media [ $40 \mathrm{~g}$ dextrin, $8 \mathrm{~g}$ corn steep liquor, $7 \mathrm{~g} \mathrm{CaCO}_{3}, 2 \mathrm{~g}\left(\mathrm{NH}_{4}\right)_{2} \mathrm{SO}_{4}, 1.4 \mathrm{ml}$ DL-lactic acid, made up to 1 liter with distilled water and adjusted to $\mathrm{pH} 7.5$ with $10 \% \mathrm{NaOH}$ ] in a $250-\mathrm{ml}$ Erlenmeyer flask, which served as the seed inocula for fermentation. Oxytetracycline was added to the media prior to inoculation at a concentration of $50 \mu \mathrm{g} / \mathrm{ml}$. The flasks were incubated in a rotary shaker $(200 \mathrm{rpm})$ at $30^{\circ} \mathrm{C}$ for $2 \sim 3$ days.

A $10 \%$ inoculation was used for the fermentation; i.e., $20 \mathrm{ml}$ of the seed inoculum for every $200 \mathrm{ml}$ of fermentation media $[100 \mathrm{~g}$ corn starch, $7.5 \mathrm{~g}$ corn steep liquor, $10 \mathrm{~g} \mathrm{CaCO}_{3}, 7 \mathrm{~g}\left(\mathrm{NH}_{4}\right)_{2} \mathrm{SO}_{4}, 2.5 \mathrm{~g} \mathrm{NH}_{4} \mathrm{Cl}, 2.0 \mathrm{~g}$ $\mathrm{MgSO}_{4}, 0.1 \mathrm{~g} \mathrm{MnSO}_{4}, 0.6 \mathrm{ml} \mathrm{CoCl} \cdot 6 \mathrm{H}_{2} \mathrm{O}(1 \% \mathrm{w} / \mathrm{v})$, $0.1 \mathrm{ml} \mathrm{NaF}(0.1 \% \mathrm{w} / \mathrm{v}), 1.0 \mathrm{ml} \mathrm{ZnSO}{ }_{4} \cdot 7 \mathrm{H}_{2} \mathrm{O}(2 \% \mathrm{w} / \mathrm{v})$ and $0.04 \mathrm{ml} \alpha$-amylase, made up to 1 liter with tap water] in a 1 liter Erlenmeyer flask. Laboratory scale fermentation was done by shake flask method at $30^{\circ} \mathrm{C}$ in a rotary shaker (200 rpm) for $8 \sim 10$ days.

\section{Extraction and Isolation}

The fermentation broth (1 liter) was saturated to $70 \%$ with technical grade $\mathrm{NaH}_{2} \mathrm{PO}_{4}$ as described in the protocol used by Petkovic [10] then extracted three times with ethyl acetate. The separation of the emulsified phase between the aqueous and organic layers was done using a refrigerated centrifuge at $6,000 \mathrm{~g}$ for 15 minutes at $4^{\circ} \mathrm{C}$. The concentrated ethyl acetate extract $(1.4 \mathrm{~g})$ was fractionated by flash chromatography using a gradient of $5 \% \mathrm{MeOH} / \mathrm{CHCl}_{3}$ to $100 \% \mathrm{MeOH}$ and gave four fractions.
Fraction I, which eluted with $5 \% \mathrm{MeOH} / \mathrm{CHCl}_{3}$, was subjected to another flash chromatographic separation. The fraction that eluted with $100 \% \mathrm{CHCl}_{3}$ was subjected to gel filtration chromatography on Sephadex LH-20, which yielded compounds $1(4.8 \mathrm{mg})$ and $2(2.9 \mathrm{mg})$ at $100 \%$ $\mathrm{CHCl}_{3}$ and $10 \% \mathrm{MeOH} / \mathrm{CHCl}_{3}$ eluants, respectively.

Fraction III that was obtained with $50 \% \mathrm{MeOH} / \mathrm{CHCl}_{3}$ was subjected to another flash chromatographic separation. The fraction that eluted with $20 \% \mathrm{MeOH} / \mathrm{CHCl}_{3}$ was further separated by preparative TLC on silica $\left(\mathrm{CHCl}_{3}\right.$ $\left.\mathrm{MeOH}-\mathrm{H}_{2} \mathrm{O}, 9: 6: 0.3\right)$ and yielded compound 3 (26.5 mg).

(rel)-4 $\beta, 8$-Dihydroxy-3 $\alpha$-hydroxymethyl- $4 \alpha$-methyl-1,2,3,4tetrahydronaphthalene-1-one (1)

Brownish yellow oil; UV (MeOH) $\lambda_{\max }(\log \varepsilon) 214$ (4.01), 259 (3.72), 335 (3.35) nm; IR (KBr disc) $v_{\max } 3404,1637$, 1454, 1347, $1252 \mathrm{~cm}^{-1} ;{ }^{1} \mathrm{H}$ and ${ }^{13} \mathrm{C}$ NMR (see Table 1); APCI-MS m/z $223[\mathrm{M}+1]^{+}, 205,187,173$ (100).

$4 \xi, 8$-Dihydroxy-3-hydroxymethyl-4 $\xi$-methyl-1,4-dihydronaphthalene-1-one (2)

Pale yellow oil; UV (MeOH) $\lambda_{\max }(\log \varepsilon) 201$ (3.89), 218 (3.79), 243 (3.45), 343 (3.19) nm; IR (KBr disc) $v_{\max } 3370$, 1681, 1607, 1456, $1136 \mathrm{~cm}^{-1} ;{ }^{1} \mathrm{H}$ and ${ }^{13} \mathrm{C}$ NMR (see Table 1); APCI-MS m/z 221 [M+1] $]^{+}, 204,203$ (100), 160.

(rel)-4 $\beta, 8$-Dihydroxy-3 $\alpha$ - $O$-[ $\alpha$-glucopyranosyl]hydroxymethyl-4 $\alpha$-methyl-1,2,3,4-tetrahydronaphthalene-1-one (3)

Pale yellow oil; UV (MeOH) $\lambda_{\max }(\log \varepsilon) 215$ (4.12), 259 (3.84), 330 (3.54) nm; IR (KBr disc) $v_{\max } 3396,2927$, 1637, 1454, 1345, 1251, $1027 \mathrm{~cm}^{-1} ;{ }^{1} \mathrm{H}$ and ${ }^{13} \mathrm{C}$ NMR (see Table 2); EIMS m/z $384[\mathrm{M}]^{+}, 187$ (100), 149, 57.

Acknowledgment MAD acknowledges the Department of Science and Technology, Republic of the Philippines for awarding her a scholarship.

\section{References}

1. Friend EJ, Hopwood DA. The linkage map of Streptomyces rimosus. J Gen Microbiol 68: 187-197 (1971)

2. Rhodes PM, Winskill N, Friend EMW. Biochemical and genetic characterization of Streptomyces rimosus mutants impaired in oxytetracycline biosynthesis. J Gen Microbiol 124: 329-338 (1981)

3. Butler MJ, Friend EJ, Hunter IS, Kaczmarek FS, Sugden DA, Warren M. Molecular cloning of resistance genes and architecture of a linked gene cluster involved in biosynthesis of oxytetracycline by Streptomyces rimosus. Molec Gen Genetics 215: 231-238 (1989) 
4. Agrawal PK, Bansal MC. Carbon-13 NMR of Flavonoids; Elsevier Science Ltd., Amsterdam, p. 283 (1989)

5. Robbers JE, Speedie MK, Tyler VE. Pharmacognosy and Pharmacobiotechnology; Williams and Wilkins, Maryland, U.S.A., p. 49 (1996)

6. Méndez C, Salas JA. Altering the glycosylation pattern of bioactive compounds. Trends Biotechnology 19: 449-456 (2001)

7. Trefzer A, Salas JA, Bechthold A. Genes and enzymes involved in deoxysugar biosynthesis in bacteria. Nat Prod Rep 16: 283-299 (1999)

8. Blanco G, Patallo EP, Braña AF, Trefzer A, Bechthold A, Rohr J, Méndez C, Salas JA. Identification of a sugar flexible glycosyltransferase from Streptomyces olivaceus, the producer of the antitumor polyketide elloramycin. Chem Biol 8: 253-263 (2001)

9. Hopwood DA, Bibb MJ, Chater KF, Kieser T, Bruton CJ, Kieser HM, Lydiate DJ, Smith CP, Ward JM, Schrempf H. Genetic Manipulation of Streptomyces (A Laboratory Manual), The John Innes Foundation, Norwich, U.K., pp. 3-5 (1985)

10. Petkovic H. An investigation of the molecular genetics of the gene cluster for oxytetracycline biosynthesis from Streptomyces rimosus. Ph.D. Thesis, University of Ljubljana: Ljubljana, Slovenia, p. 88 (1998) 